\title{
FTP: FastTest PlugIn, aplicación para crear grandes bancos de preguntas de diferentes tipos para la plataforma Moodle FTP: FastTest PlugIn, aplication to create big question banks of different types for the Moodle platform
}

\author{
Huerta Gómez de Merodio, Milagros ${ }^{1}$, Fernández Ruiz, Manuel Alejandro ${ }^{2}$ \\ milagros.huerta@uca.es,manuelalejandro.fernandez@uca.es
}

\author{
${ }^{1}$ Departamento de Ingeniería Mecánica y Diseño Industrial \\ Universidad de Cádiz \\ Puerto Real, España
}

\author{
${ }^{2}$ Departamento de Ingeniería Industrial e Ingeniería Civil \\ Universidad de Cádiz \\ Algeciras, España
}

\begin{abstract}
Resumen- Durante este último año, la manera de impartir la docencia ha cambiado de forma radical, sobre todo para los centros cuya docencia era totalmente presencial. Uno de los retos a los que se han enfrentado los profesores ha sido tener que preparar exámenes online de manera que los alumnos no copiaran las respuestas. La pregunta que muchos profesores se hicieron durante el confinamiento era cómo evaluar el aprendizaje de los alumnos, evitando que copien los resultados, si se les examina a través del ordenador. En este artículo se explica cómo se ha resuelto parte de este problema. Para ello se ha recuperado una aplicación que se comenzó a desarrollar en 2011 usando el programa Excel. Esta aplicación ayuda a generar muchos problemas/preguntas iguales, pero con diferentes datos, para la plataforma Moodle. Con el objetivo de poder ofrecerlo al resto de la comunidad educativa, se ha mejorado la aplicación, de manera que sea fácil de entender para usuarios que no se le dé bien con la informática. En este artículo se hace una breve descripción de cómo funciona, así como los resultados obtenidos tras hacer una encuesta a profesores a los que se les ha impartido un curso sobre ella.
\end{abstract}

Palabras clave: eLearning, Evaluación online, Cuestionarios Moodle, Educación superior, COVID'19

\begin{abstract}
This last year, the teaching methodology has drastically changed, especially for those centres with entirely in-person education. One of the challenges that teachers have faced has been preparing online exams in which students could not copy the answers. Many teachers asked ourselves during lockdown how to evaluate students' learning while preventing the solutions from being copied, provided that the exams were online. This paper explains how to solve part of this problem. To do so, an application that began to be developed in 2011 using Excel has retrieved. This app helps to generate plenty of similar problems/questions with different figures for the Moodle platform. The application has improved to offer it to the educational community so that it is easier to understand for users who are not computer literate. This paper provides a brief description of how it works and the results obtained after surveying teachers who have taken a course on it.
\end{abstract}

Keywords: eLearning, Online assessment, Moodle quiz, Higher education, COVID'19

\section{INTRODUCCIÓN}

Moodle es una plataforma de aprendizaje, robusta y segura, que proporciona una gran variedad de herramientas centradas en el estudiante. Es de libre acceso, tiene más de 270 millones de usuarios y se utiliza en 247 países de todo el mundo (Estadísiticas Moodle, 2020).

De entre todas las actividades que tiene esta plataforma, la de cuestionarios es una de las más utilizada para evaluar a los estudiantes. Estas actividades permiten hacer preguntas a los estudiantes de diferentes tipos: Opción múltiple, Verdadero y Falso, Emparejar, Palabra Perdida, Calculada, Respuesta Corta, etc. Todas las preguntas se organizan por categorías en bancos de preguntas, pudiendo utilizarse en diferentes cursos. Una de las ventajas que tiene preparar este tipo de actividades es que se corrigen automáticamente, de manera que solo hay que descargar la calificación final. Lo que más trabajo puede costar es preparar las preguntas. En primer lugar, se debe pensar qué se quiere preguntar y cómo se va a diseñar la pregunta. Posteriormente, hay que crearlas en la plataforma en la que se desea trabajar con los alumnos, en este caso Moodle.

El uso de cuestionarios Moodle es una de las herramientas para la evaluación online recomendadas recientemente para tiempos de COVID'19 (García-Peñalvo et al., 2020). En este artículo, indican que uno de los inconvenientes que tiene este tipo de evaluación es la configuración de los mismos, pues es más bien tediosa, si se quiere hacer un gran banco de preguntas para que cada alumno tenga una pregunta diferente.

Cuando se habla del tiempo total dedicado a preparar las preguntas, en lo que más tiempo se debería invertir es pensar bien la redacción de esas preguntas y dedicar lo mínimo a digitalizarlas. Actualmente existen varios plugins para Moodle que ayudan a preparar los bancos de preguntas. Por ejemplo, el formato GIFT permite crear algunos tipos de preguntas y hay que crearlas una a una. El inconveniente es que se debe tener una plantilla y hay que seguir una serie de reglas y símbolos, lo cual no resulta sencillo para todos. Además, si se falla en uno solo, no funciona y no se importan las preguntas. 
En este artículo se describe una aplicación desarrollada para mejorar y optimizar el tiempo de elaborar los bancos de preguntas para la plataforma Moodle, de manera que el 95\% del tiempo que se dedique a preparar la pregunta y el 5\% restante a digitalizarlo y preparar el cuestionario. Actualmente, la aplicación está desarrollada en Excel y funciona bien para el sistema operativo Windows, pero se está desarrollando una nueva versión para que se pueda usar en cualquier sistema operativo y sin necesidad de tener Excel.

\section{CONTEXTO}

En España, el 14 de marzo de 2020, se decretó el estado de alarma, debido a la pandemia provocada por el virus SARSCoV-2, causante del COVID'19. Este estado de alarma obligó a todo el mundo a permanecer las casas durante unos meses. Por este motivo, se tuvieron que cerrar los centros de todos los niveles educativos, de un día para otro, sin "previo aviso" y se tuvo que reorganizar de manera urgente tanto la forma de impartir la docencia, como la evaluación.

Con respecto a la impartición de la docencia, aquellos profesores que ya estaban acostumbrados al uso de las nuevas tecnologías en sus clases, tuvieron menos problemas para adaptarse que los que no las conocían. Ahora bien, para lo que no había tanta preparación era a evaluar a los alumnos, estando ellos en su casa, y no teniendo control de cómo realizaban el examen, si eran ellos los que lo estaban haciendo, o si se comunicaban a través de algún dispositivo por internet para hacer el examen en conjunto.

Al impartir la docencia de manera síncrona, los alumnos se conectaban, pero no era fácil saber si estaban atentos o si se enteraban de lo que se estaba explicando, pues no tenían obligación de tener su cámara activa. En varias ocasiones se detectó que, algunos alumnos, se limitaban a conectar el ordenador, sin prestar atención, pues al terminar la clase, no se despedían si cerraban la sesión. Mientras algunos profesores se esforzaban por transmitir lo mejor posible las materias, algunos alumnos se preparaban para un aprobado general o se organizaban para tratar de copiar durante el examen online.

Cuando se confirmó que los exámenes de la convocatoria de junio iban a ser online, los profesores tuvieron que prepararse para evaluar a los alumnos de una manera diferente. Había varias opciones, algunas posibilidades eran: mandar trabajos sobre el contenido impartido; hacer exámenes orales (inviable para clases con muchos alumnos); preparar exámenes online, sabiendo las limitaciones que teníamos para controlar que no copiaran durante la realización de los mismos.

Para tratar de evitar esto, o si copiaban, que no lo pudieran hacer bien, se recuperó un trabajo iniciado en el 2011 (Huerta et al., 2011). Este trabajo consistía en una hoja Excel que ayudaba a preparar muchos problemas iguales, pero con datos diferentes. De esa manera, cada alumno tendría que realizar sus propios cálculos y, usando la plataforma Moodle, se corregirían solos. La herramienta se creó para que los alumnos tuvieran muchos problemas similares y pudieran practicar. El trabajo más laborioso era programar el problema en Excel, pero luego, se generaban las preguntas y se importaban a Moodle en muy poco tiempo. Esto se hacía usando el tipo de preguntas Cloze de Moolde, que permite en una misma pregunta, solicitar al estudiante más de una respuesta, tipo numérica, respuesta corta e incluso opción múltiple.
Durante la pandemia, tras recuperar dicho trabajo preparado en Excel y ver la necesidad de muchos compañeros de hacer los exámenes online, con preguntas tipo test y otros formatos, se decidió mejorar la aplicación. Además de los problemas para los que ya estaba funcionando, se pensó usar como base esa hoja Excel, para crear otros tipos de preguntas. Para ello se incluyó una pantalla en la que fuera sencillo e intuitivo introducir los datos, sin tener que saber nada de programación y sin necesitar recordar códigos como necesita el formato GIFT.

Gracias a la aprobación de un Proyecto de Innovación Docente de la Universidad de Cádiz, para el curso 2020/2021, se ha podido desarrollar la aplicación. Antes de darla a conocer a la comunidad Moodle de acceso gratis, se han realizado cursos de formación sobre el uso de la misma a los profesores de dicha universidad. El objetivo de dichos cursos era conocer el grado de satisfacción con la misma, Además, era necesario comprobar el correcto funcionamiento con un gran número de usuarios. Para ello, se han elaborado unas encuestas a los profesores, los resultados de las cuales se muestran más adelante.

En el siguiente apartado se hace una breve descripción de cómo funciona la aplicación. Posteriormente se comentan los resultados de las encuestas realizadas a los profesores y, al final, se indican las conclusiones.

\section{DESCRIPCIÓN}

La aplicación FastTest-PlugIn está desarrollada bajo el Programa Excel, en el lenguaje de programación VBA (Visual Basic for Applications). Es una herramienta que ayuda a crear muchas preguntas de diferentes tipologías: Opción Múltiple con una sola posible respuesta correcta (o varias); Verdadero Falso; Emparejar; Respuesta Corta; Palabra Perdida; Ensayo; y Cloze.

El idioma original en el que está desarrollada la aplicación es el español, aunque también está en inglés y francés. Con el fin de poder llegar a más usuarios, se ha traducido a los idiomas: italiano, portugués y alemán, usado el traductor de Google. Está previsto ir corrigiendo estas traducciones en futuras versiones.

Con esta aplicación, el usuario (normalmente docente) puede crear de manera rápida y fácil un gran banco de preguntas, para luego importarlos en la plataforma Moodle con solo subir un archivo, que genera la aplicación.

Además, cada Banco de Preguntas se puede Exportar a un documento de texto, por si el usuario quiere tener las preguntas en este formato e imprimirlas para un examen escrito. Se puede exportar a otra hoja Excel para tener una copia de seguridad y se pueden importar preguntas guardadas previamente en ese formato.

En la Figura 1 se muestra la pantalla de Datos Generales, en la que se puede seleccionar el tipo de pregunta que se quiere preparar, mediante un menú desplegable. Una vez seleccionado el tipo de pregunta, se puede ir a la pantalla Formularios (donde se introducen las preguntas una a una), o Banco de Preguntas (donde se almacenan todas las preguntas generadas). En esta pantalla se puede generar también el nombre de la Categoría en la que se desea que se incluyan las preguntas que se elaboren. También están las distintas opciones generales que tiene la aplicación: exportar e importar las preguntas a un archivo Excel, como copia de seguridad, generar el archivo XML que hay que importar a Moodle, o generar un documento de texto para poder imprimir las preguntas. 


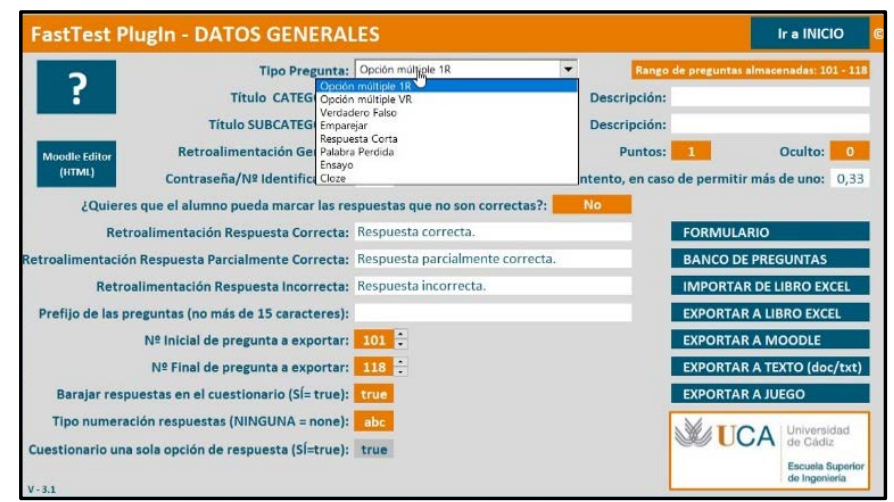

Figura 1: Pantalla de Datos Generales de la aplicación

En la Figura 2 se muestra la pantalla de Formularios para el tipo de preguntas Opción Múltiple 1R (una posible Respuesta correcta). Hay un ejemplo de una pregunta con cálculos numéricos, que está escrita con fórmulas de Excel (utilizando la función Aleatorio.Entre) de manera que se puedan guardar hasta 100 preguntas iguales, pero con los números diferentes, pulsado tan solo el botón de GUARDAR PREGUNTAS.

Esta opción de generar muchas preguntas iguales, pero con distintos datos, también se puede hacer con variables de texto. Sólo es cuestión de preparar las fórmulas como se explica en algunos los video tutoriales de la aplicación.

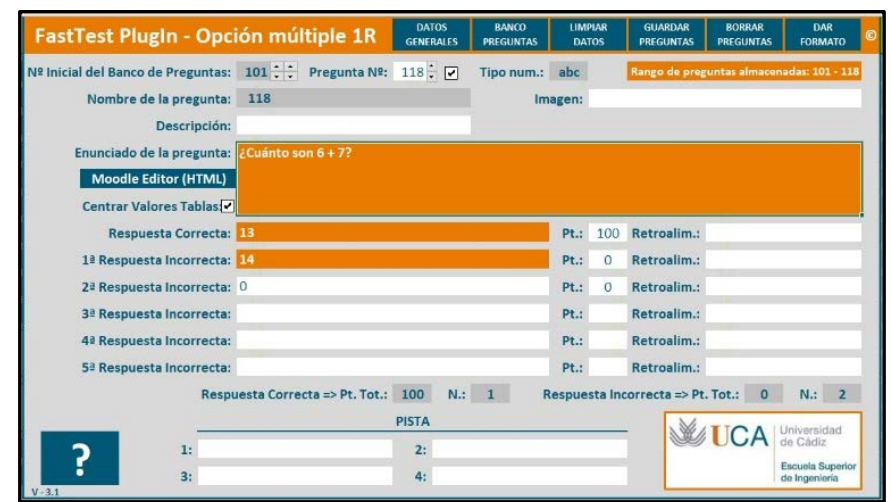

Figura 2: Pantalla: Formulario Opción Múltiple 1 respuesta

En la Figura 3 se muestra la pantalla de Formularios para el tipo de preguntas Palabra Perdida. Este tipo de preguntas, cuesta trabajo entender cómo configurarlas en la plataforma Moodle, mientras que con esta aplicación es más intuitivo cómo se tiene que generar la pregunta. Por supuesto, también se pueden generar muchas preguntas similares usando las funciones de Excel. Eso ya dependerá de los conocimientos que tenga el usuario de las muchas funciones de Excel.

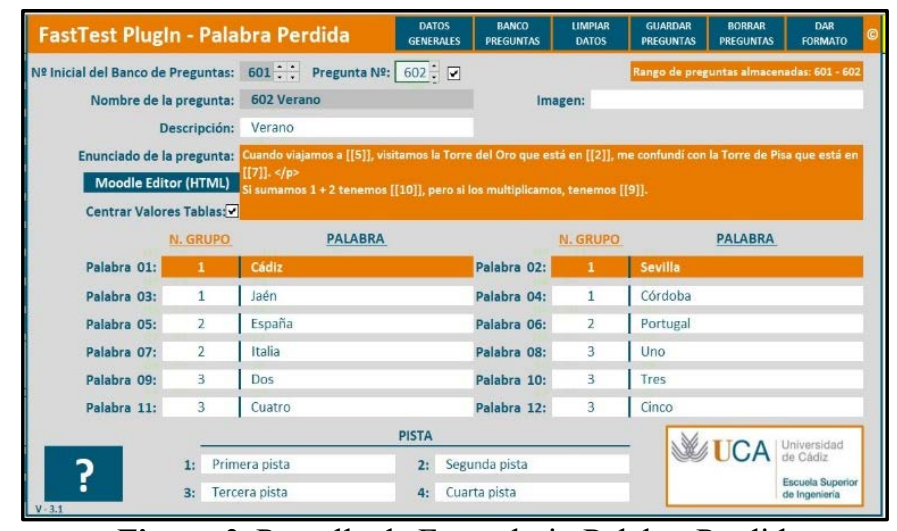

Figura 3: Pantalla de Formulario Palabra Perdida
Al tener todos los datos de la pregunta ajustados a la pantalla, la elaboración de este tipo de preguntas resulta más sencilla. El procedimiento recomendado es: que se escriba la frase entera; posteriormente, la palabra que se quiera poner para que el alumno tenga que elegir de un menú desplegable, se pone en una de las casillas numeradas; y, dentro del enunciado de la pregunta, el número de la palabra entre doble corchete [[X]]. Todas las palabras que tengan un mismo $\mathrm{n}^{\circ}$ de grupo serán las que aparezcan en el menú desplegable para que el alumno elija.

Además, si se quiere insertar una imagen, tanto en el enunciado como en los apartados que Moodle admite imágenes, la aplicación genera el código de inserción de la imagen. Para ello, la imagen debe estar compartida de manera pública, con Google Drive o Dropobox. Esto es recomendable para tener control total sobre las imágenes que se quieren usar.

En la Figura 4, se muestra la pantalla en la que se introducen las preguntas tipo Cloze, o respuestas anidadas. En este tipo de preguntas se pueden incluir: respuesta corta, numérica y opción múltiple. La configuración de este tipo de preguntas es mucho más abierta que las demás, pudiendo incluir en un mismo enunciado varias preguntas de diferentes tipos. Para los que quieran utilizar los códigos Cloze, la aplicación dispone de unos botones que recuerdan cómo se codifica cada tipo de pregunta. Se pueden copiar, para hacer las modificaciones que sean necesarias y adaptar la pregunta a las necesidades de cada uno.

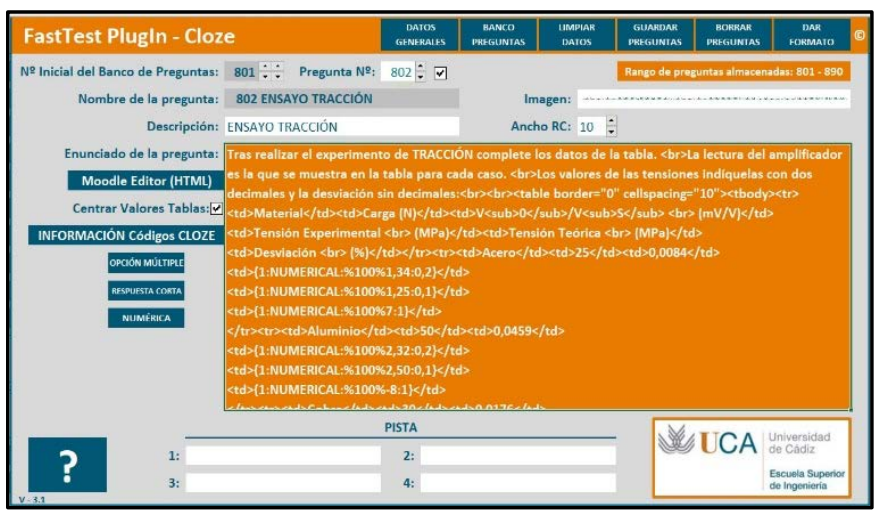

Figura 4: Pantalla de una pregunta tipo Cloze

En la Figura 5, se puede ver cómo queda el ejemplo de la pregunta Cloze del ejemplo anterior en la plataforma Moodle.

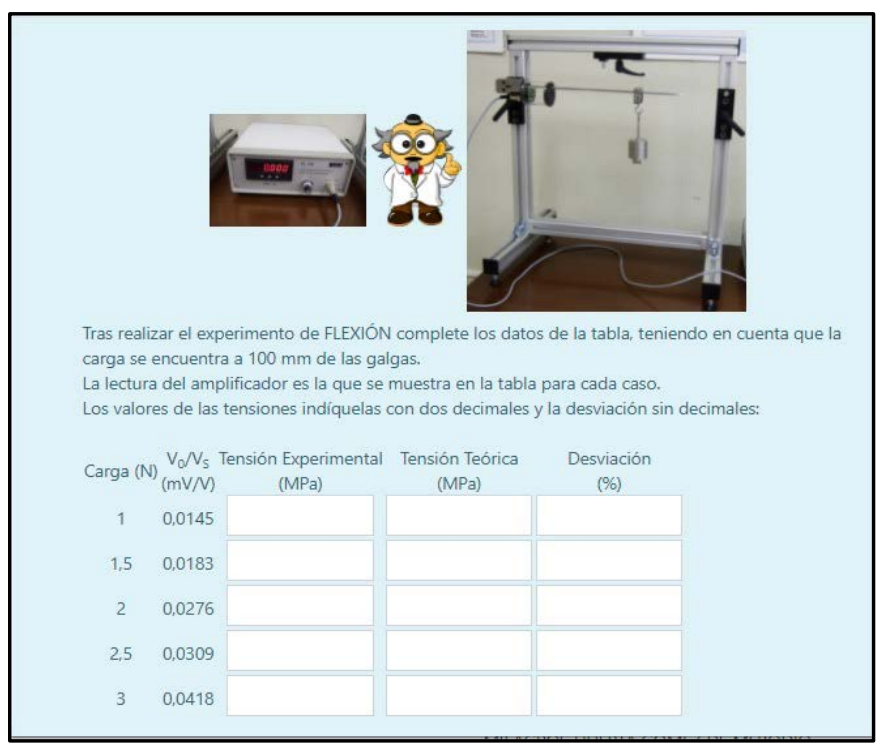

Figura 5: Pregunta tipo Cloze en la plataforma Moodle 
Aunque parezca complicado por todo el código que se ve en el enunciado de la pregunta de la Figura 4, se ha configurado utilizando un editor de Moodle para preguntas Cloze (Kohn et al., n.d.). Este tipo de preguntas se ha utilizado, por ejemplo, para completar las prácticas de laboratorio que los alumnos no podían desarrollar, por el tema de las distancias de seguridad. Como se muestra en la figura, incluso se pueden incluir tablas. Además, se ha utilizado una codificación especial, para hacer que todos los huecos que aparecen en las posibles respuestas tengan el mismo tamaño, de manera que su longitud, no sea una pista para poder acertar la respuesta.

En algunas asignaturas, los alumnos han asistido al aula para realizar las prácticas. Por las medidas COVID'19, para evitar que estuvieran mucho tiempo juntos, realizaron cada una de las prácticas tomando una única medida $\mathrm{y}$, con la plataforma Moodle, se configuró un cuestionario en el que al alumno se le proporcionaba varias medidas, de cada práctica, y así pudiera confeccionar el informe completo.

Para la evaluación de las prácticas de laboratorio, se ha utilizado la metodología Flip-GET (Huerta et al., 2019), junto con la aplicación FastTest-PlugIn, para crear los cuestionarios Moodle y así poder tener una mejor evaluación de los alumnos.

En la Figura 6 se muestra el Editor Cloze de Moodle. Ayuda a generar preguntas de este tipo, sin necesidad de conocer cómo se codifican. En colores oscuros se muestra el cuadro donde se introducen los datos de la pregunta, y en el fondo, en clarito y entre corchetes, se muestra el código Cloze que ha incluido el editor para que Moodle interprete bien la pregunta. El usuario no tiene que escribir este código, pues el Editor de Cloze (Kohn et al., n.d.) lo hace tras seleccionar el tipo de pregunta y rellenar los datos en el formulario.

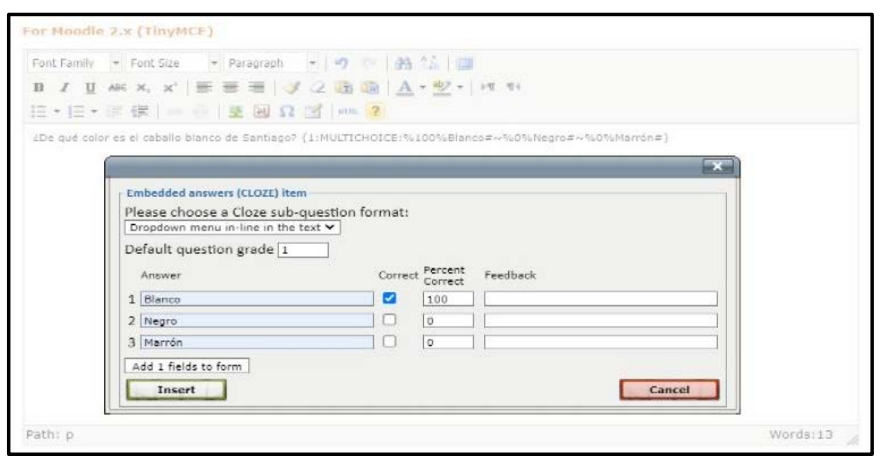

Figura 6: Crear pregunta tipo Cloze con Moodle

\section{RESUltados}

La muestra de población con la que se ha hecho la encuesta es con profesores de universidad. Por lo que los resultados hay que enmarcarlos en este contexto. Se han realizado dos encuestas, una antes de conocer la aplicación y otra después.

A la fecha de la redacción de este artículo, se han realizado dos cursos de formación, a un total de 148 profesores, de todas las áreas de conocimiento de la universidad y de todas las edades. Actualmente se está impartiendo una tercera edición, con 74 profesores, la cual finaliza a finales de junio, por lo que solamente se les ha pasado la primera encuesta.

En primer lugar, destacar que el 79\% de los profesores que han realizado los cursos utilizan el sistema operativo Windows, mientras que el 19\% utiliza Mac Os. El 2\% restante son usuarios de Linux (3 profesores). Al empezar el curso se les dijo que esta aplicación aún no está preparada para trabajar en ese sistema operativo, por lo que uno se dio de baja del curso y los otros dos finalizaron comentando que sí usarían la aplicación, aunque uno de ellos comentó que seguiría usando los formatos GIFT, ya conocidos y comentados anteriormente. Además, el $85 \%$ de los profesores afirma utilizar el Excel como programa para crear hojas de cálculo, por lo que ya están familiarizados con el entorno de trabajo de la aplicación, un $8 \%$ utiliza otro tipo de programas y un $7 \%$ afirma no usar programas de hojas de cálculo para nada. Este último dato es de profesores de las áreas de Humanidades, Ciencias Sociales y Ciencias Jurídicas.

\section{A. Resultados antes de conocer la aplicación}

En primer lugar, para conocer el uso de los cuestionarios Moodle en sus asignaturas, se preguntó a los profesores con qué frecuencia los utilizaban antes del confinamiento. El 19\% respondió que no los utilizaba para nada y el 26\% que los utilizaba muy poco. El resto, respondió que con mucha o relativa frecuencia.

De los que respondieron que no los utilizaban para nada, un $52 \%$ respondió que porque no los conocían o porque no sabía cómo se tenían que configurar. Un 36\% respondió que no los veía útiles para sus asignaturas. De entre estos profesores, cuando se les preguntó si habían cambiado su forma de ver los cuestionarios Moodle, después del Confinamiento, un $60 \%$ respondió que sí había cambiado y que ahora los utilizarán más. Un 12\% afirmaron aún no haberlos usado.

Con respecto a si es fácil y rápido introducir las preguntas en la plataforma Moodle, muy pocos respondieron que sí. La mayoría (un $42 \%$ ) respondieron que ni fácil ni difícil. En la Figura 7 se muestran los resultados de dicha pregunta. Lo cual da indicios a que era necesario desarrollar una aplicación que facilite este trabajo.

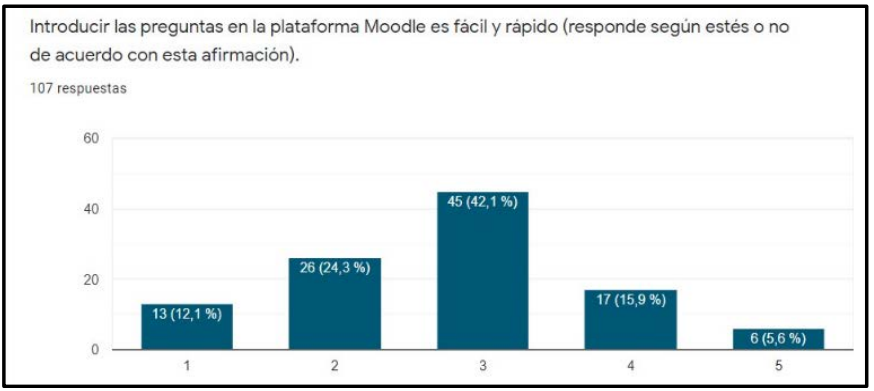

Figura 7: ¿Es fácil introducir preguntas en Moodle?

A la pregunta sobre el tipo de preguntas que utilizaban, antes y después del confinamiento, las respuestas fueron similares. Un 96\% las preguntas tipo Opción Múltiple, entre un 50-60\% las de tipo Verdadero/Falso, un 50\% las de Respuesta Corta y entre un $25-30 \%$ las de emparejar. El resto de tipos de preguntas, no supera el $15 \%$.

Además de todo esto, se preguntó a los profesores sobre el uso de imágenes en sus bancos de preguntas. Un 52\% afirma haber usado alguna vez las imágenes en los cuestionarios. De entre ellos, un $60 \%$ afirma que le resulta sencillo introducirlas, el resto afirman que no es sencillo, además de que perdían los enlaces de las imágenes, al llevar las preguntas de un curso para otro. Del $48 \%$ restante, un $19 \%$ afirma desconocer que se podían utilizar, un $17 \%$ que no las utiliza porque les resulta laborioso y el $12 \%$ que no las utilizan porque no les resulta interesante para sus asignaturas. 


\section{B. Resultados después de conocer la aplicación}

Una vez finalizado el curso, se pasó otra encuesta a los profesores. A esta encuesta respondieron menos, pues algunos profesores no pudieron seguir el curso y decidieron dejarlo, para poder hacerlo cuando dispusieran de más tiempo. De los que sí lo hicieron, no todos respondieron a esta encuesta, lo que hay que tener en cuenta a la hora de analizar estos datos, ya que no se sabe si esto ha sido por falta de tiempo por parte del profesorado, o por no gustar la aplicación.

Aun así, de los profesores que sí respondieron a la encuesta, cuando se les preguntó por el tipo de preguntas que piensan usar con la aplicación FastTest-PlugIn, se ve que se su percepción sobre los tipos de preguntas varía, pues ahora muchos se han animado a usar otros tipos de preguntas, además de las de Opción Múltiple y Verdadero Falso. En la Figura 8 se muestran los resultados a esta pregunta.

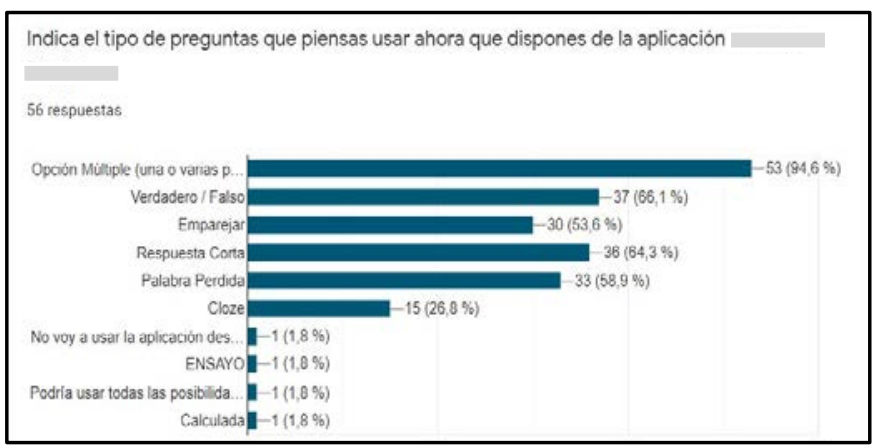

Figura 8: Tipos de preguntas que van a usar con la aplicación

Además, hay que decir que en la versión de la aplicación que se ofreció a estos profesores en las primeras ediciones del curso, aún no estaba incluida la opción Cloze, ni la opción de guardar muchas preguntas con datos variables (opción que sustituye al tipo de pregunta Calculada de Moodle). En la edición del curso que actualmente está finalizando, algunos profesores ya han respondido al cuestionario y, sobre el uso de preguntas tipo Cloze, tras conocer la aplicación, se ha duplicado.

De entre todas las respuestas, uno de los profesores comenta que no va a usar la aplicación. El ámbito en el que imparte clases es de Humanidades y dice no haber usado nunca hojas de cálculo. Además, hay que decir que, cuando se puso la aplicación a disposición de los profesores de la primera edición del curso, aún tenía algunos errores que se han ido corrigiendo según se han ido detectando. Se tiene que destacar esto, porque este mismo profesor, cuando se le indica que comente lo que le parece la aplicación, escribió:

\section{“Al principio, me gustó la aplicación y pensé que sería muy útil. Luego, (también confieso que, por mi culpa, quizás no le he dedicado el tiempo necesario), a mí al menos no me ha resultado amigable ni intuitiva, además de que me ha dado errores varias veces".}

Es muy importante tenerlo en cuenta, porque para llegar a cambiar la forma de trabajar de algunas personas, hay que asegurarse que lo que les ofreces funciona bien, pues de otro modo el resultado puede ser el contrario al deseado.

Con respecto a si es fácil y rápido introducir las preguntas en la plataforma Moodle utilizando la aplicación, la percepción de los que respondieron ha cambiado. El $75 \%$ de los profesores han respondido que les resulta muy fácil o bastante fácil. En la Figura 9 se muestran los resultados.
Cuando se les preguntó si les resulta sencillo introducir imágenes con la aplicación, sólo un $12 \%$ respondió que no, casi un $70 \%$ respondió que sí, mientras que el resto, han respondido que no han tenido tiempo de probarlo. Por otro lado, cuando se les pregunta si les parece interesante usar imágenes utilizando la aplicación, el 90\% respondió que sí.

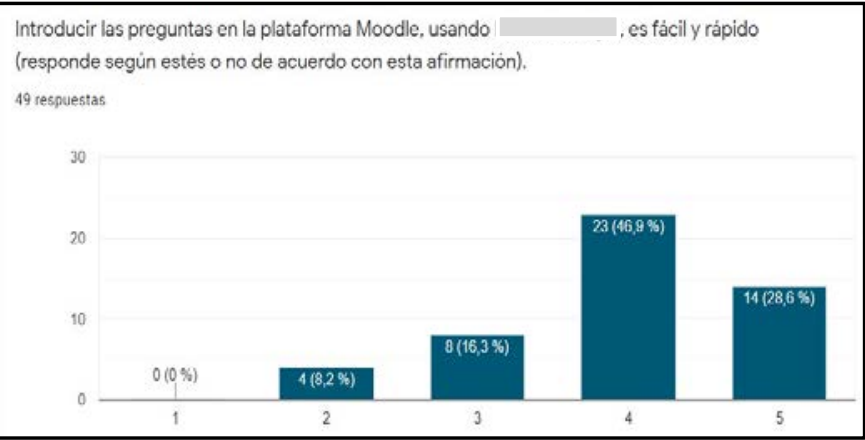

Figura 9: ¿Es fácil introducir preguntas con FastTest-PlugIn?

Por último, se dejó un espacio para que cada profesor comentara qué le parece la aplicación. A continuación, se trascriben algunos de los comentarios:

"Es una aplicación que facilita enormemente la entrada cuestionarios de Moodle. Por otro lado, felicito a la responsable del curso y al equipo que ha llevado a cabo la programación de la aplicación. Ha sido de los mejores cursos de formación del PDI al que he tenido la oportunidad de asistir."

"Es una aplicación muy potente e intuitiva. Además, los videotutoriales son muy didácticos."

"Muy interesante la aplicación y una forma cómoda de disponer de las preguntas disponibles en una base de datos. También me ha gustado la opción de pasarla a texto para ocasiones en las que se tenga que hacer el examen presencial, por ejemplo. Ya lo he puesto en práctica para una actividad docente. Enhorabuena!!”

"El desarrollo de esta aplicación me parece un trabajo excelente. La recomendaré a mis compañeros, sin duda. Su aprendizaje requiere algo de tiempo, pero los resultados son inmediatos. ¡Enhorabuena!”

"Al principio parece más complicada de lo que luego es, cuando ya la vas trabajando más. Sí, de preguntas de todo tipo para es muy recomendable."

"Me parece una herramienta estupenda que nos ayuda a crear y organizar mejor nuestras preguntas para Moodle, y sobre todo hace más fácil la utilización de muchos tipos de preguntas en los cuestionarios. No lo recomendaria, iya lo he recomendado! Me esperaba que fuera más recortado en cuanto a prestaciones, pero todo lo contrario. Muchas gracias por el curso y por haber creado el plugin."

"Puede servir a quien encuentre la interfaz de Moodle poco amigable; además, permite almacenar bancos de preguntas independientemente de la plataforma Moodle."

"Muy interesante y eficaz, por supuesto que la recomendaría. Me esperaba algo menos elaborado, por lo que ha sido una grata sorpresa." 


\section{CONCLUSIONES}

En primer lugar, es importante comentar que ninguno de los autores que participan en este Proyecto de Innovación Docente es Ingeniero Informático, sino que han estudiado Ingeniería de Organización Industrial e la Ingeniería de Caminos Canales y Puertos. Para crear la aplicación se ha utilizado VBA Excel, con ayuda de video tutoriales que hay en Internet. Por lo que cabe concluir que lo importante de la aplicación no es tanto la programación que hay detrás de ella, sino la idea, pues se trata de un programa relativamente sencillo, con sus limitaciones.

Viendo los resultados de la encuesta, parece que el haber creado la aplicación en este entorno ha sido una buena elección, pues el porcentaje de usuarios que pueden utilizarla es muy elevado. Dado que el objetivo es llegar a todos, como trabajo futuro, se quiere desarrollar la aplicación en un lenguaje de programación multiplataforma, para así poder llegar al 100\% de los profesores que deseen utilizarla.

Con esa aplicación, se ha conseguido que algunos profesores conozcan otros tipos de preguntas que se pueden generar en la plataforma Moodle. Además, al ver la facilidad con la que se pueden generar, es muy probable que las utilicen más en su docencia, ya no solo para evaluar a los alumnos en exámenes finales, sino para generar preguntas para evaluación continua o incluso para que puedan practicar y hacer muchos problemas iguales, pero con datos diferentes.

Por otro lado, el uso de las imágenes no está muy extendido en este tipo de ejercicios, pero puede ser muy útil y hacer más completa la evaluación. Al dar ideas de cómo incluir imágenes con esta aplicación para no perder el enlace de un curso para otro, y poder hacer además que las preguntas sean más flexibles, hay profesores que ya han empezado a implementarlas en sus cuestionarios.

La versión 3.0 de la aplicación, en la que se incluyen las preguntas tipo Cloze, se sacó justo cuando los profesores de la segunda edición del curso estaban finalizándolo. Por este motivo, hay que esperar a que termine la edición del curso que está actualmente, para ver si el uso de este tipo de preguntas se extiende a más usuarios. Tal y como comenta uno de los profesores en la encuesta, cuando se le pregunta sobre la aplicación:

"Si, es una aplicación útil, la versión 3 que se acaba de publicar, mejora. Es muy funcional, la recomendaría y no me lo esperaba, ayudará mucho a quien la emplee."

Con respecto a la evaluación de los alumnos, el hecho de tener un gran banco de preguntas similares con diferentes datos, no evita que el examen lo pueda realizar otra persona con más conocimientos que el alumno, pero ayuda a que, al menos, no copien las respuestas entre ellos o si lo hacen, tengan que saber sustituir los datos de cada enunciado o tengan más dificultad al haber muchas preguntas muy similares.

Tras hacer una búsqueda intensiva sobre los diferentes plugins de Moodle para crear los bancos de preguntas, no se ha encontrado ninguno tan completo, ni que cumpla con lo que este plugin ofrece. Sí se han encontrado varios plugins (Singh, 2020), intentando facilitar esta labor de crear los bancos de preguntas de manera sencilla, pero suelen requerir códigos informáticos (Duque, 2019), por lo que se puede concluir que este plugin va a tener una muy buena acogida en la comunidad Moodle.

\section{AgRADECIMIENTOS}

Agradecer a la Unidad de Innovación Docente de la Universidad de Cádiz por la aprobación de este Proyecto de Innovación Docente, y así poder llevarlo a cabo durante el presente curso académico 2020/2021.

Nuestro más sincero agradecimiento, también, a los profesores de esta universidad, que han participado en los cursos de formación de la aplicación. Tanto por sus aportaciones para mejorarla, como por su paciencia, con los pequeños errores que ha ido teniendo la app y que se han ido solventando. En resumen, por ser los "probadores beta". También a los que han colaborado con sus ideas y con la corrección del inglés y francés.

Se ha creado un canal de YouTube, exclusivo para todo lo relacionado con la aplicación, desde el que se puede descargar tanto la última versión, como los video tutoriales de la misma. En la carpeta compartida con todo el mundo que tenga el enlace (Huerta, 2020), se muestra el índice con el contenido de los video tutoriales, así como el enlace para descargarse la última versión. Los documentos de esta se irán actualizando según vayan se desarrollando nuevas versiones o vídeo tutoriales.

\section{REFERENCIAS}

Duque, C. T. (2019). Mr. Moodle: How Can I Make The Most Of XML In Moodle Quizzes? https://www.lmspulse.com/2019/mr-moodle-how-can-imake-the-most-of-xml-in-moodle-quizzes/\#comment2168326

Estadísiticas

Moodle. https://stats.moodle.org/index.php?

(2020)

García-Peñalvo, F. J., Corell, A., Abella-García, V., \& Grande, M. (2020). La evaluación online en la educación superior en tiempos de COVID'19. Education in the Knowledge Society, 21(May), 1-26. https://doi.org/10.14201/eks.23013

Huerta, M. (2020). Documentos para FastTest PlugIn y enlace a la aplicación. Google Drive. https:/drive.google.com/drive/folders/1PZti8DYAKcaC PkDTEykFY_SwkTMjgpRV

Huerta, M., Dodero, J. M., Mora, N., \& Portela, J. M. (2019). Flip-Game Engineering and Technology Methodology. In Innovative Trends in Flipped Teaching and Adaptive Learning (pp. 77-109). igi-global.com. https://doi.org/10.4018/978-1-5225-8142-0.ch005

Huerta, M., Portela, J. M., Pastor, A., Otero, M., Velázquez, S., \& González, P. (2011). Cómo preparar una gran colección de problemas virtuales, para que los alumnos aprendan. VIII Jornadas Internacionales de Innovación Universitaria, 1-7. http://hdl.handle.net/11268/1671

Kohn, P. D. K., Glombitza, A., \& Skuta, A. (n.d.). Moodle CLOZE editor. tuebingen.de/quiz/htmlarea/index.php

Singh, J. (2020). Do You Want To Easily Create A Large Number Of Questions In Your Moodle Course? https://www.lmspulse.com/2020/gift-format-moodlequiz-scripting/\#gift 